DR-33

\title{
SYNTHESIS OF FURFURAL FROM PRE-BALL-MILLED SUNFLOWER HUSKS
}

\section{O. S. Taniya, ${ }^{1,2}$ L. K. Sadieva, ${ }^{1}$ S. Santra, ${ }^{1}$ A. F. Khasanov, ${ }^{1,2}$ M. Rahman, ${ }^{1}$}

\section{S. Kovalev, ${ }^{1}$ D. S. Kopchuk, ${ }^{1,2}$ G. V. Zyryanov, ${ }^{1,2}$ V. L. Rusinov, ${ }^{1,2}$ O. N. Chupakhin ${ }^{1,2}$}

${ }^{1}$ Ya. Postovsky Institute of Organic Synthesis UB RAS, S. Kovalevskoy / Akademicheskaya St., 20/22, Yekaterinburg, 620990, Russia;

${ }^{2}$ Ural Federal University of the first President of Russia B. N. Yeltsin. Mira St., 19. Yekaterinburg, 620002, Russia. E-mail: olgataniya@yandex.ru

\begin{abstract}
Furfural (FF) is an essential natural building block for the synthesis of non-petroleumderived chemicals and solvents, including furan and tetrahydrofuran (THF), providing an alternative to petrochemical production of these compounds based on biomass by 1,4-butanediol dehydration[1]. 5 Hydroxymethilfurfural (5-HMF) as a by-product of xylose dehydrogenation in the production of furfural and its substituted derivatives, on the one hand, are precursors for the production of liquid alkanes (C7 C15), which serve as diesel fuel components, on the other hand, are important components and pharmacologically active compounds associated with a wide range of biological activity[2,3]. Quantum chemical calculations, namely, the calculation of energy barriers for xylose dehydrogenation, made it possible to present the most probable mechanism[4] from a significant list of alternatively presented in the literature (Fig.1).
\end{abstract}

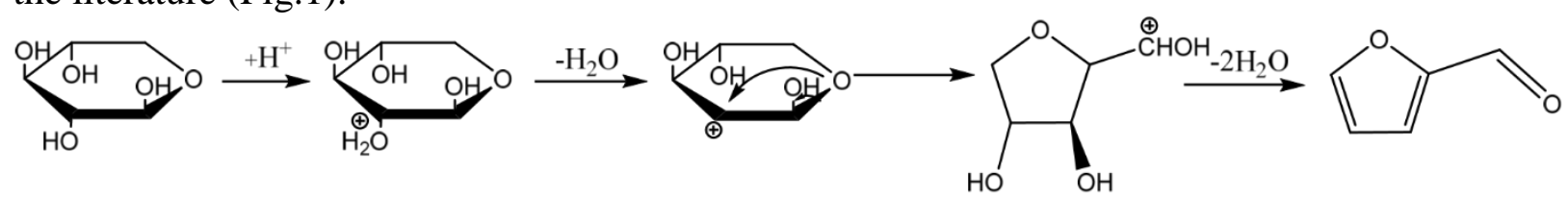

Figure 1. The most likely mechanism for acid hydrolysis of polysaccharides, resulting in furfural.

All pentosans containing fibrous material can theoretically be used as raw materials for the production offurfural. However, the industrial production of furfural requires a pentosan content of at least $18-20 \%$ [5]. Sunflower husk is among the top ten agricultural residues containing about $25 \%$ pentosans and is a convenient model for the development of synthesis methods due to the composition typical of straw and wood waste[6]. The industrial yield of furfural from the husks of sunflower consists of only $8-9 \%$.

\section{References}

1. Chheda J.N., Román-Leshkov Y., Dumesic J.A. Production of 5-hydroxymethylfurfural and furfural by dehydration of biomass-derived mono- and poly-saccharides // Green Chem. Royal Society of Chemistry, 2007. Vol. 9, № 4. P. 342350 .

2. Galkin K.I., Ananikov V.P. Towards Improved Biorefinery Technologies: 5 Methylfurfural as a Versatile C 6 Platform for Biofuels Development // ChemSusChem. John Wiley \& Sons, Ltd, 2019. Vol. 12, № 1. P. 185-189.

3. Galkin K.I. et al. Critical Influence of 5-Hydroxymethylfurfural Aging and Decomposition on the Utility of Biomass Conversion in Organic Synthesis // Angew. Chemie Int. Ed. John Wiley \& Sons, Ltd, 2016. Vol. 55, № 29. P. 83388342.

4. Nimlos M.R. et al. Energetics of Xylose Decomposition as Determined Using Quantum Mechanics Modeling // J. Phys. Chem. A. American Chemical Society, 2006. Vol. 110, № 42. P. 11824-11838.

5. Mansilla H.D. et al. Acid-catalysed hydrolysis of rice hull: Evaluation of furfural production // Bioresour. Technol. Elsevier, 1998. Vol. 66, № 3. P. 189-193.

6. Cai C.M. et al. Integrated furfural production as a renewable fuel and chemical platform from lignocellulosic biomass // J. Chem. Technol. Biotechnol. John Wiley \& Sons, Ltd, 2014. Vol. 89, № 1. P. 2- 10. 